\title{
Radial Mode Piezoelectric Transformer Design for Fluorescent Lamp Ballast Applications
}

\author{
Eric M. Baker, Weixing Huang, Dan Y. Chen, Fellow, IEEE, and Fred C. Lee, Fellow, IEEE
}

\begin{abstract}
In a ballast circuit, the piezoelectric transformer (PT) is used to replace the conventional inductor-capacitor resonant tank saving valuable space and cost. During circuit operation, a very high voltage is required to initially ignite the lamp while during sustained operation the voltage requirements are significantly reduced. With ballast in mind, a design process has been developed to optimize a radial mode piezoelectric transformer or Transoner ${ }^{\circledR}$ to fit a specific application while simultaneously providing highly efficient performance and the capability to provide ZVS to the switches. The design procedure was verified by a custom-designed PT operating in a 32-W ballast.
\end{abstract}

Index Terms-Ballast circuit, inductor-capacitor resonant tank, piezoelectric transformer (PT), Transoner.

\section{INTRODUCTION}

I $\mathrm{N}$ ORDER to power an incandescent lamp, one must only provide a voltage source, which can yield the power level prescribed by the on-state filament resistance. In contrast, fluorescent lamps require a certain voltage to ignite the lamp and a quite different voltage to sustain a given power level. This is the function of a lamp ballast circuit.

A conventional electronic ballast circuit usually consists of a parallel or series resonant converter, which contains a magnetic inductor and a high-voltage capacitor connected in series. Piezoelectric transformers (PT) can potentially be used to replace the conventional $L-C$ resonant tank to save cost, weight and packaging height [1]-[4]. Previous ballast design using the piezoelectric transformer required selecting from readily available models not always mated to a specific application [2], [3]. Rarely has one seen a situation in which the piezoelectric transformer could be custom designed to fit each application. In this paper, results of such an endeavor will be given for a $32-\mathrm{W}$ $120-\mathrm{V}$ standard line ballast. A radial mode piezoelectric transformer or Tansoner (a trade name by Face Electronics, USA) will be designed to fit the aforementioned ballast. To the authors' knowledge, a radial-mode PT is the only type of PT that has been reported to be capable of providing output power in the $32-\mathrm{W}$ range as required by the application. In the paper, design equations will be provided with an outline of the step-by-step

Manuscript received January 23, 2004; revised August 12, 2004. This work was supported by the Center for Innovation Technology and Face Electronics, Norfolk, VA, CPES, Virginia Tech, ERC Shared Facilities, and the National Science Foundation under Award EEC-9731677. Recommended by Associate Editor F. Blaabjerg.

E. M. Baker is with Crown International, Inc., Elkhart, IN 46515 USA.

W. Huang is with Picor Corporation, North Smithfield, RI 02896 USA.

D. Y. Chen is with National Taiwan University, Taipei 100, Taiwan, R.O.C. (e-mail: chend@cc.ee.ntu.edu.tw).

F. C. Lee is with the Center for Power Electronics Systems, Virginia Polytechnic Institute and State University, Blacksburg, VA 24061 USA.

Digital Object Identifier 10.1109/TPEL.2005.854068

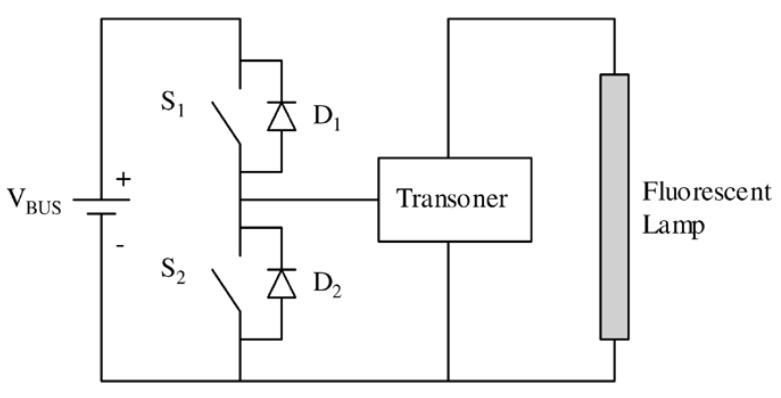

Fig. 1. Half-bridge ballast circuit topology using a Transoner.

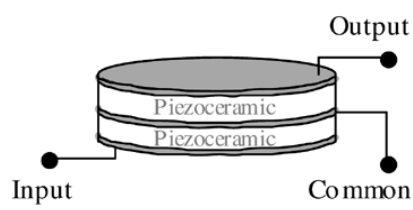

Fig. 2. Physical construction of Transoner.

procedure used to design a Transoner. A prototype Transoner based on the design process was fabricated by Face Electronics and then tested experimentally in the ballast circuit. The specific goals of the design process require that the Transoner meets proper voltage gain, efficiency, and the ability to provide a zerovoltage switching condition for the circuit shown as Fig. 1.

\section{PT Equivalent CirCuit Model AND Considerations IN POWER CONVERSION EFFICIENCY}

The accepted equivalent circuit model for a piezoelectric transformer or PT has been well developed in [3] and [5]-[7]. This model is an electrical circuit, representative of the properties exhibited by two or more layers of piezoceramic physically coupled together. Electrical connections are made through metallic physical connections on the surface of each layer. Fig. 2 shows a two-layer Transoner and the physical electrical connections. Transoner can be constructed to have multiple primary and secondary layers of different thickness [8], as the application requires. Fig. 3 captures the simplified equivalent circuit model common to all piezoelectric transformers.

Given the above equivalent circuit model, a resistive load can be connected in parallel with the output capacitance, $\mathrm{Cd} 2$. It has been reported that when the load match (1), the PT efficiency is the highest [2], [5]

$$
\mathrm{RL}=\frac{1}{\omega_{s} \cdot \mathrm{Cd} 2} .
$$

It should be noted that a matching network can sometimes be added between the PT and the load to increase the PT efficiency. 


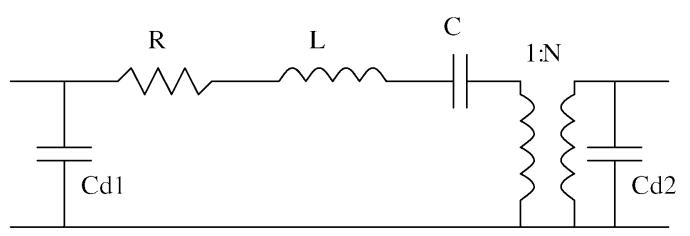

Fig. 3. Piezoelectric transformer equivalent circuit model.

TABLE I

Equivalent Circuit Model Parameters

\begin{tabular}{c|c}
\hline \multicolumn{2}{c}{ CZ-3 Equivalent Circuit Model Parameters } \\
\hline Cd1 & $10.2 \mathrm{nF}$ \\
$\mathrm{R}$ & $901 \mathrm{~m} \Omega$ \\
$\mathrm{L}$ & $1.67 \mathrm{mH}$ \\
$\mathrm{C}$ & $2.89 \mathrm{nF}$ \\
$\mathrm{Cd} 2$ & $2.79 \mathrm{nF}$ \\
$\mathrm{N}$ & 4.73 \\
\hline
\end{tabular}

However, this technique is not considered in this paper as it adds additional components to the design. In this design process it is mandated that no additional elements should be added and thus (1) will be used as one of the constraints used in this design process for Transoner.

In order to visualize the result in (1), a three-dimensional (3-D) plot can be constructed using the applied frequency, $f_{s}$, and load resistance, RL, as the independent axes and the resulting efficiency as the dependant axis. As an example, the Face Electronics CZ-3 Transoner was chosen, and its equivalent circuit model parameters are shown in Table I.

In Fig. 4 the efficiency of the CZ-3 Transoner is plotted against the load resistance, RL, and the driving frequency, $f_{s}$. By carefully following lines of constant frequency, the highest efficiency for a given frequency is achieved when the load resistance follows the formulation of (1).

There are two defining resonant points of a piezoelectric transformer. The first is the result of when there is a short circuit applied to the output. The second occurs when there is an open circuit load. The equations defining these frequencies appear as (2) and (3), respectively. Operating the piezoelectric transformer with any load resistance assures that the respective resonant frequency will appear between these two limits

$$
\begin{aligned}
\omega_{\mathrm{SC}} & =\frac{1}{\sqrt{L \cdot C}} \\
\omega_{\mathrm{OC}} & =\frac{1}{\sqrt{L \cdot\left(C^{-1}+\left(N^{2} \cdot \mathrm{Cd} 2\right)^{-1}\right)^{-1}}} .
\end{aligned}
$$

\section{EFFiciency With CONSIDERATION OF Dielectric LosS}

In order to better predict the efficiency of a piezoelectric transformer, the dielectric loss of the material can also be considered. This can be modeled as in [5] where the loss is seen as a frequency dependant resistance, $\mathrm{R}_{\mathrm{Cdx}}$, in parallel with both the input and output capacitances, $\mathrm{Cd} 1$ and $\mathrm{Cd} 2$. In order to calculate this loss, $\tan \delta$, the dissipation factor of the

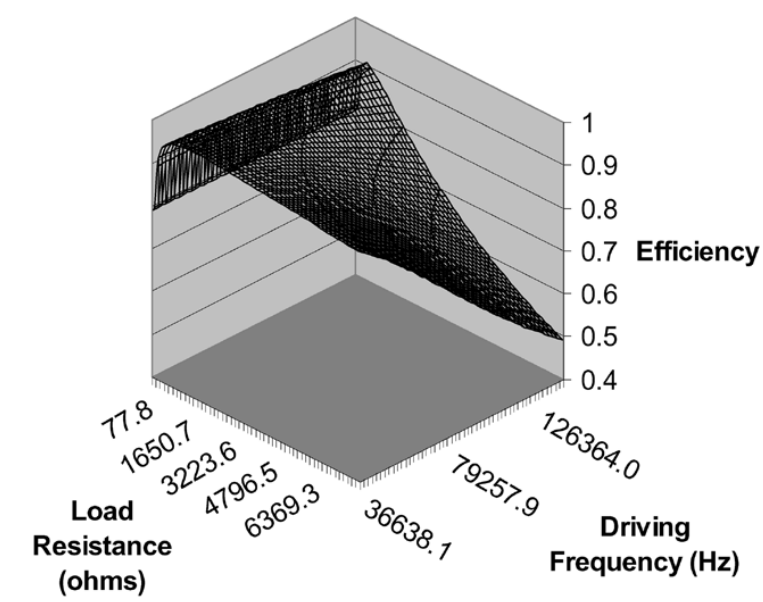

Fig. 4. Theoretical efficiency of the Prototype CZ-3 PT.

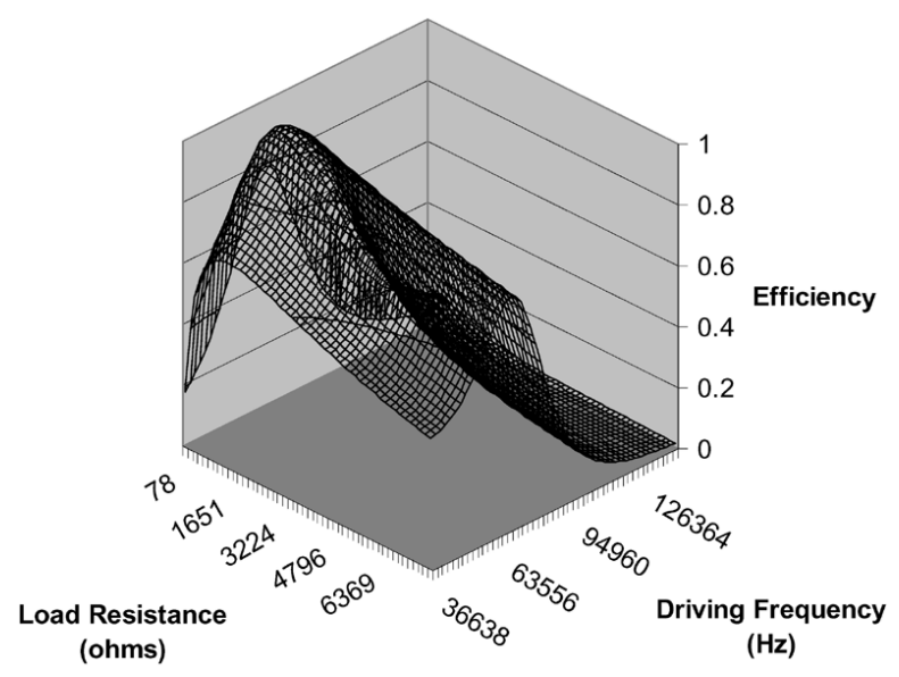

Fig. 5. Theoretical efficiency of the CZ-3 PT including dielectric losses.

piezoceramic is used as specified by the material manufacturer, as in

$$
R_{\mathrm{Cdx}}=\frac{1}{\omega_{S} \cdot \operatorname{Cd} x \cdot \tan \delta} .
$$

The result of this added loss, creates both an overall lower predicted efficiency and a change in the shape of the plot. Fig. 5 shows the efficiency plot including the dielectric losses of the materials. At frequencies both above and below resonant frequency range, the shape is dramatically different. Fig. 6 is the result of calculating the difference between the two efficiency curves. As can be seen, the difference is negligible near the resonant frequency range. This result is also true for any PT when the dissipation factor or $\tan \delta$ of the material is relatively small, which is observed in most all piezoceramics.

If it is assumed that the piezoelectric transformer is operated at or near the resonant frequency for a particular load, the relationship described by (1) holds true even when the dielectric losses of the material are taken into account. A piezoelectric transformer is essentially a high-Q resonant tank circuit. The efficiency is the best when it's operated near its resonant frequency. dc input power cannot pass through and input harmonic frequency components are suppressed. 


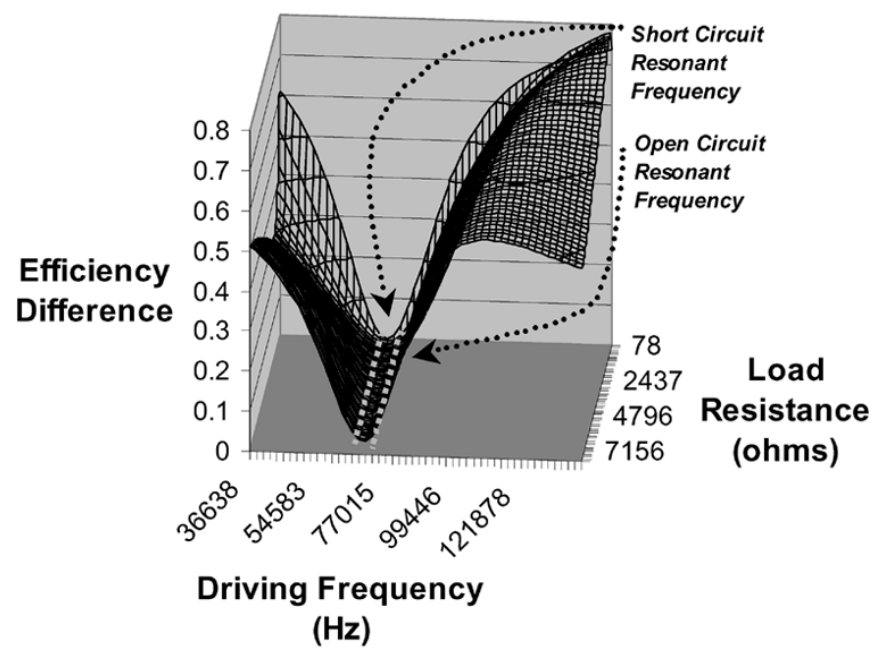

Fig. 6. Efficiency difference is negligible between $\mathrm{f}_{\mathrm{SC}}$ and $\mathrm{f}_{\mathrm{OC}}$.

\section{TRANSONER DESIGN EQUations}

The equivalent circuit model described above evolves from the physical construction of the piezoelectric transformer and the material characteristics. Equations (5)-(10) show the intimate relationship between each material characteristic and physical dimension as it pertains to Transoner as developed in [6] and [7]. Table II contains the definitions of the various material coefficients

$$
\begin{aligned}
\mathrm{Cd} 1 & =\frac{N_{1} \cdot \pi \cdot r^{2} \cdot \varepsilon_{33}^{T} \cdot\left(1-\frac{d_{31}^{2}}{\varepsilon_{33}^{T} \cdot S_{11}^{E}}\right)}{t_{1}} \\
R & =\frac{\sqrt{2 \cdot \rho \cdot S_{11}^{E^{3}} \cdot\left(N_{1} \cdot t_{1}+N_{2} \cdot t_{2}\right)}}{16 \cdot r \cdot Q_{m} \cdot\left(N_{1} \cdot d_{31}\right)^{2}} \\
L & =\frac{\rho \cdot S_{11}^{E^{2} \cdot\left(N_{1} \cdot t_{1}+N_{2} \cdot t_{2}\right)}}{8 \cdot \pi \cdot\left(N_{1} \cdot d_{31}\right)^{2}} \\
C & =\frac{16 \cdot r^{2} \cdot\left(d_{31} \cdot N_{1}\right)^{2}}{\pi \cdot S_{11}^{E} \cdot\left(N_{1} \cdot t_{1}+N_{2} \cdot t_{2}\right)} \\
\mathrm{Cd} 2 & =\frac{N_{2} \cdot \pi \cdot r^{2} \cdot \varepsilon_{33}^{T} \cdot\left(1-\frac{d_{31}^{2}}{\varepsilon_{33}^{T} \cdot S_{11}^{E}}\right)}{t_{2}} \\
N & =\frac{N_{1}}{N_{2}} .
\end{aligned}
$$

\section{Transoner Design Process}

The relationship described in (1) is very important, as it initiates the Transoner design process. In order to best illustrate the design process, a specific example will be completely worked out in the body of this paper.

Each linear fluorescent lamp has a fixed impedance during sustained operation that is considered resistive, as the lamp voltage and current are in phase. By utilizing (1) and a given frequency, one can solve for the necessary capacitance, $\mathrm{Cd} 2$, the Transoner should exhibit for maximum efficiency.

Table III contains a summary of relevant circuit characteristics for a hypothetical ballast design.

The full-wave rectified source voltage will exhibit an average of $155 \mathrm{~V}$ with the addition of a bulk dc bus capacitor. The circuit topology will be a simple half-bridge, which will directly drive
TABLE II

MATERIAL COEFFICIENTS

\begin{tabular}{c|c}
\hline \multicolumn{2}{c}{ Material Symbols and Definitions } \\
\hline$\rho$ & Density \\
$\varepsilon^{\mathrm{T}}{ }_{33}$ & Permittivity \\
$\mathrm{Q}_{\mathrm{m}}$ & Mechanical Quality Factor \\
$\mathrm{d}_{31}$ & Piezoelectric Coefficient \\
$\mathrm{S}^{\mathrm{E}}$ & Elastic Compliance \\
$\tan _{11}$ & Dissipation Factor \\
$\mathrm{N}_{\mathrm{R}}$ & Radial Mode Frequency Constant \\
$\mathrm{t}_{1}$ & Primary Layer Thickness \\
$\mathrm{t}_{2}$ & Secondary Layer Thickness \\
$\mathrm{N}$ & Number of Primary Layers \\
$\mathrm{N}_{1}$ & Number of Secondary Layers \\
\hline & Radius of the Layers \\
\hline
\end{tabular}

TABLE III

RELEVANT CiRCUIT CHARACTERISTICS FOR A HYPOTHETICAL BALLAST DESIGN

Design Example: Ballast Circuit Specifications

\begin{tabular}{c|c}
\hline Circuit Input Voltage & 120Vrms 60Hz AC \\
Lamp Resistance & $500 \Omega$ \\
Lamp Power & $32 \mathrm{~W}$ \\
\hline
\end{tabular}

the Transoner as in Fig. 1. Hence, the voltage gain requirement for the Transoner can be calculated from the power level and the lamp resistance as in (11). In this case, the required gain $A v_{\mathrm{PT}}$ is approximately $2.0 \mathrm{~V} / \mathrm{V}$. With this in mind, the design process can begin

$$
A v_{\mathrm{PT}}=\frac{\sqrt{P_{\mathrm{LAMP}} \cdot R_{\mathrm{LAMP}}}}{0.4 \cdot V_{\mathrm{BUS}}}
$$

\section{A. Step One-Build the First Layer}

The approximate resonant frequency of a radial-mode piezoelectric transformer can be calculated through the use of its diameter or radius as in [2] and [6]. Equation (12) below utilizes the radial frequency constant, $\mathrm{N}_{\mathrm{R}}$, as specified by the manufacturer, to calculate the fundamental operating frequency equating one full wavelength of the resonant frequency to the material diameter. Table IV shows the material characteristics for APC-841 piezoceramic [9], which will be used in this design example

$$
f_{r} \cong \frac{N_{R}}{D} \text {. }
$$

In this example, the diameter of the prototype Transoner is selected to be $825-\mathrm{mil}$ or $2.096 \mathrm{~cm}$ based on available materials and reasonable size. Ultimately the diameter of Transoner should be selected through thermal analysis considering the 
TABLE IV

MATERIAL CHARACTERISTICS FOR APC-841 PIEZOCERAMIC

\begin{tabular}{c|c}
\hline \multicolumn{2}{c}{ APC-841 Properties } \\
\hline$\rho$ & $7.6 \mathrm{~g} / \mathrm{cm}^{3}$ \\
$\varepsilon^{\mathrm{T}}{ }_{33}$ & $1350 \varepsilon_{0}$ \\
$\mathrm{Q}_{\mathrm{m}}$ & 1400 \\
$\mathrm{~d}_{31}$ & $10910^{-12} \mathrm{~m} / \mathrm{V}$ \\
$\mathrm{S}_{11}^{\mathrm{E}}$ & $11.710^{-12} \mathrm{~m}^{2} / \mathrm{N}$ \\
$\mathrm{N}_{\mathrm{R}}$ & $2055 \mathrm{~m} / \mathrm{s}$ \\
$\tan \delta$ & $0.35 \%$ \\
\hline
\end{tabular}

power level and efficiency of the circuit. Solving (12), it is found that the approximate resonant frequency, $\mathrm{f}_{\mathrm{r}}$, will be $100 \mathrm{kHz}$. Given $\mathrm{f}_{\mathrm{r}}$, (1) can be solved yielding the output capacitance as in (13). Equation (9) can then be utilized to yield the thickness of the secondary layer(s). For this example $\mathrm{N}_{2}$ is chosen to be unity for simplicity. The result can be seen in

$$
\begin{aligned}
\mathrm{Cd} 2 & =\frac{1}{\omega_{r} \cdot R_{\mathrm{LAMP}}}=3.2 \mathrm{nF} \\
t_{2} & =\frac{N_{2} \cdot \pi \cdot r^{2} \cdot \varepsilon_{33}^{T} \cdot\left(1-\frac{d_{31}^{2}}{\varepsilon_{33}^{T} \cdot S_{11}^{E}}\right)}{\mathrm{Cd} 2} \cong 0.050 \mathrm{in} .
\end{aligned}
$$

\section{B. Step Two-Add Input Layer and Calculate Voltage Gain}

By adding an input layer, the equivalent circuit model is complete. The voltage gain of the Transoner can be plotted as a function of both driving frequency, $\mathrm{f}_{\mathrm{s}}$, and primary layer thickness, $t_{1}$, by calculating the complete equivalent circuit model as a function of $t_{1}$ using (5)-(10). A practical range of material thickness is from 10-mil to 200-mil. Fig. 7 shows the resulting plot in three-dimensions. The minimum voltage gain required for this design was calculated to be $2.0 \mathrm{~V} / \mathrm{V}$ from (11). As can be seen, there is no primary layer thickness within the range that can be selected to provide this magnitude of gain.

In order to increase the voltage gain, one method is to increase the internal turn ratio within the equivalent circuit model by adding primary layers. This process can be repeated until the voltage gain is as desired. In this case, only two primary layers were needed. The resulting voltage gain plot can be seen in Fig. 8.

By taking a slice of the plot of Fig. 8 at the minimum voltage gain, a two-dimensional (2-D) surface projection can be generated which allows one to easily see where in the $\left(t_{1} \times f_{s}\right)$ plane a solution exists. Using this technique Fig. 9 was generated.

\section{Step Three-Find an Acceptable Primary Layer Thickness}

Analyzing Fig. 9, it can be seen that the entire range of primary layer thickness can meet the voltage gain requirement. In order to narrow down a smaller range of thickness, more constraints must be included.

With the choice of a half-bridge topology [1]-[5], zero voltage switching can be achieved as in [1] and [2] if enough dead-time is provided and the relationship seen as (15) is met.

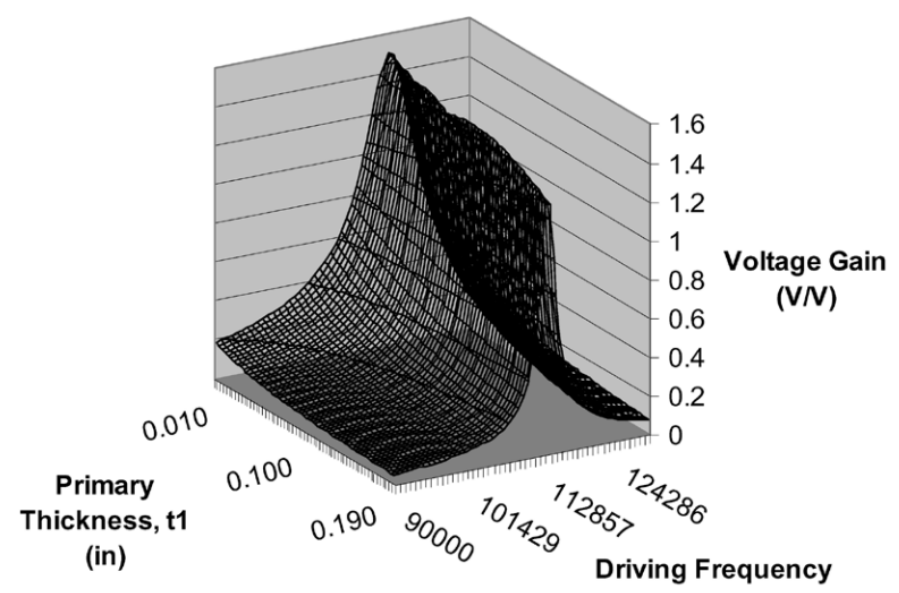

$(\mathrm{Hz})$

Fig. 7. Voltage gain of the prototype versus primary layer thickness and frequency, (with only one primary layer).

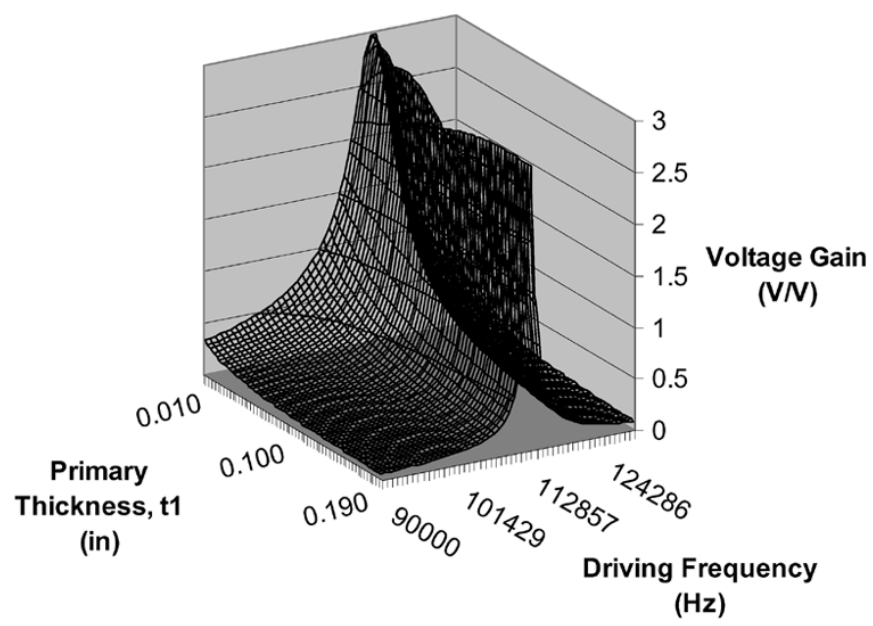

Fig. 8. Voltage gain of prototype versus primary layer thickness and frequency (with two primary layers).

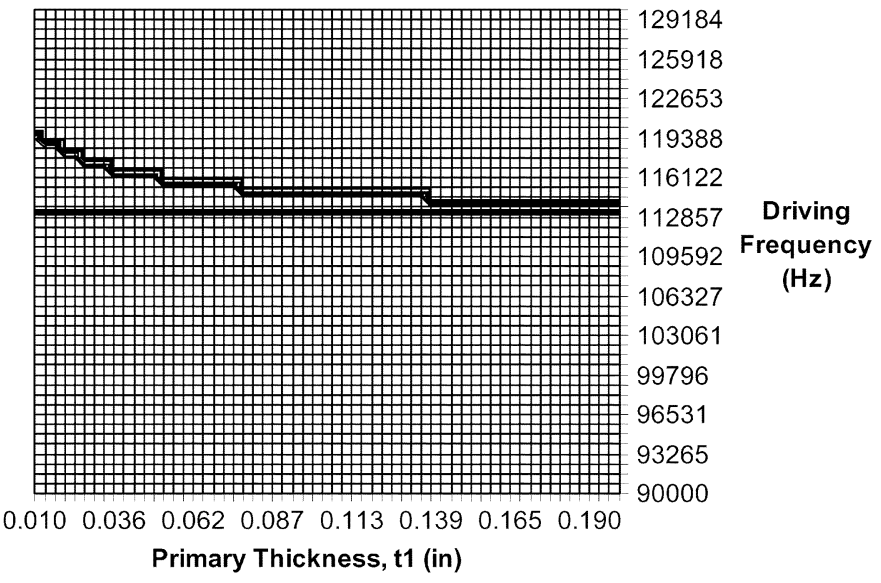

Fig. 9. Region where the voltage gain is greater than the minimum.

In short, the energy within the internal inductance, $\mathrm{L}$, should be great enough to charge/discharge the internal capacitance, C, and the input capacitance, Cd1, during the dead-time period. By solving (15) for the internal inductor current, a critical value (16) evolves which must be surpassed in order for ZVS to take place. The peak inductor current can be approximated 


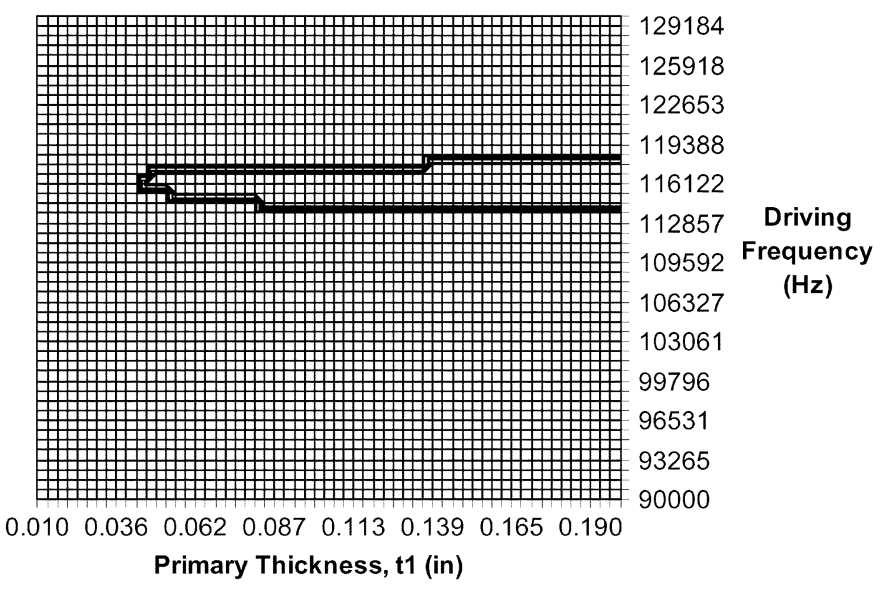

Fig. 10. Region where inductor current is great enough to achieve ZVS.

through the use of (17) as in [1] and [2] where $Z_{\text {in }}$ is the input impedance of the piezoelectric transformer excluding $\mathrm{Cd} 1$, but including the lamp load, and $\mathrm{A}$ is the ratio of the rise/fall time to the period. Using the same technique as Fig. 9, a 3-D plot of the peak inductor current has been sliced where it exceeds the minimum or critical value and is shown as Fig. 10

$$
\begin{aligned}
\frac{1}{2} \cdot L \cdot \Delta i_{L_{\text {peak }}}^{2} & \geq \frac{1}{2} \cdot \mathrm{Cd} 1 \cdot V \mathrm{bus}^{2} \cdot\left(1+\frac{\mathrm{Cd} 1}{C}\right) \\
\Delta i_{L_{\text {peak }}} & \geq \sqrt{\frac{\mathrm{Cd} 1 \cdot(C+\mathrm{Cd} 1)}{L \cdot C}} \cdot V \text { bus } \\
\Delta i_{L_{\text {peak }}}\left(f_{s}\right) & =\frac{2 \cdot V \mathrm{bus}}{\pi \cdot\left|Z_{\text {in }}\left(f_{s}\right)\right|} \cdot \frac{\sin (\pi \cdot A)}{\pi \cdot A} \sin \left(\angle Z_{\text {in }}\left(f_{s}\right)\right) .
\end{aligned}
$$

One final consideration should be for efficiency. To better enhance the appeal of using a piezoelectric transformer in place of the conventional $L-C$ resonant tank, the efficiency of the circuit should not be sacrificed. The efficiency of the prototype Transoner can be plotted in three dimensions with both the primary layer thickness and frequency as the dependent axes. A limit can be set for the minimum allowable efficiency based on the Transoner size and power level. Here, a limit was set at $90 \%$ or better and the efficiency plot is sliced at this level allowing a 2-D projection as before. This plot is shown as Fig. 11 .

In order to create the smallest range of choices for primary layer thickness, the three plots are then overlapped to find the common choices of both $t_{1}$ and $f_{s}$, which are elements of all three 2-D projections. Any choice within this overlapped region will provide a useful Transoner for the application. Primary thickness, $t_{1}$, should be made as small as possible within the region of solution such that the finished Transoner has minimal interference between vibration modes [2]. Fig. 12 shows the complete solution region in the $\left(t_{1} \times f_{s}\right)$ space.

\section{Step Four-Choose a Primary Layer Thickness and Calculate the Complete Circuit Model}

From Fig. 12, the range of primary layer thickness, which will work with our circuit, varies over quite a large range. This range may be further narrowed by increasing the level of the efficiency minimum or by placing other constraints on the design. For this example, the primary thickness was chosen to be 60-mil. Thus, the complete Transoner has two primary layers of 60-mil each

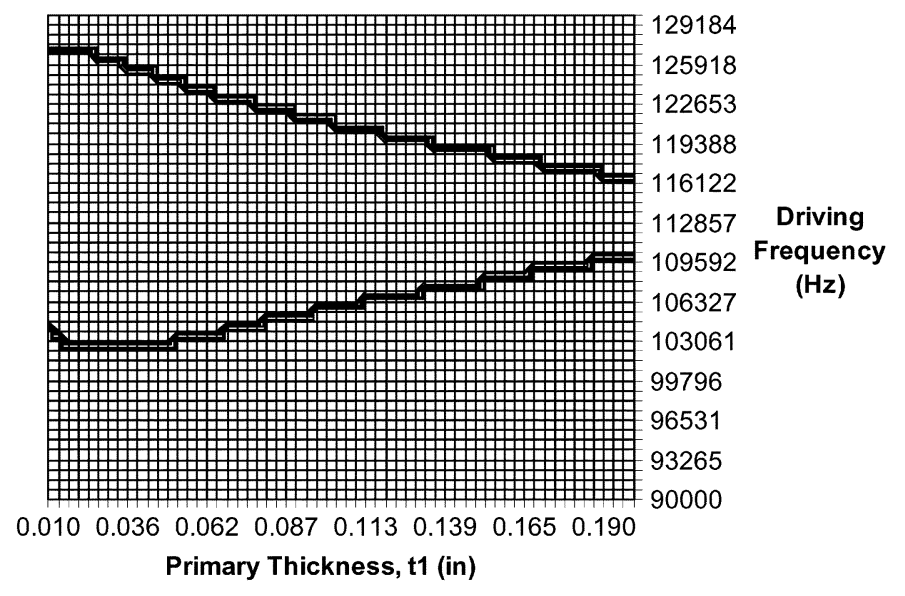

Fig. 11. Region where efficiency is greater than the preset minimum.

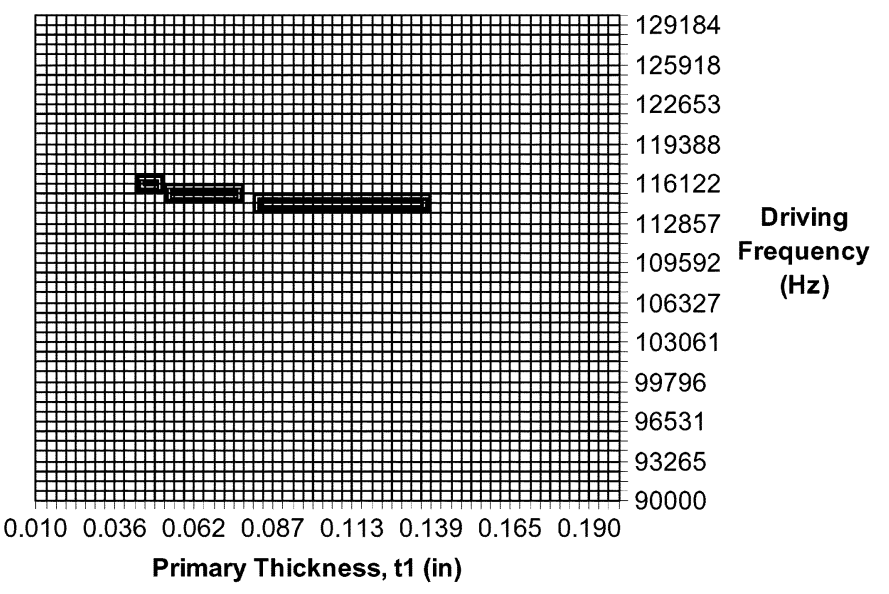

Fig. 12. Solution region that meets all requirements.

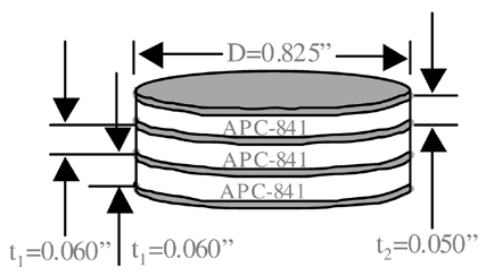

Fig. 13. Physical construction of the prototype transoner.

and a secondary layer of 50-mil. The overall diameter is 825 mil. A simple diagram of the prototype is shown as Fig. 13.

It should be pointed out that lamp ignition voltage gain was not placed as a design constraint in the proposed design process. Using this type of PT for this type of lamp, the lamp starting voltage requirement is easy to meet. Therefore, to avoid unnecessary complication in an already complicated procedure, it's not included in the design constraint and the sample designs have never had problems starting the lamps.

\section{EXPERIMENTAL RESULTS}

In order to verify the design procedure, Face Electronics manufactured the sample described in this design procedure designating it as Transoner VTB-1. The measured equivalent circuit parameters appear in Table V. As can be seen, most of the parameters match very well except for the equivalent 
TABLE V

MEASURED EQUIVALENT CIRCUIT PARAMETERS

\begin{tabular}{c|c|c|c}
\hline VTB-1 Equivalent Circuit Parameters & Theoretical & Measured & Error $(\%)$ \\
\hline $\mathrm{Cd} 1(\mathrm{nF})$ & 4.9 & 4.61 & $-5.9 \%$ \\
$\mathrm{R}(\Omega)$ & 1.91 & 2.21 & $+15.7 \%$ \\
$\mathrm{~L}(\mathrm{mH})$ & 3.78 & 2.36 & $-37.6 \%$ \\
$\mathrm{C}(\mathrm{pF})$ & 527 & 930 & $+76.5 \%$ \\
$\mathrm{Cd} 2(\mathrm{nF})$ & 2.97 & 2.90 & $-2.4 \%$ \\
$\mathrm{~N}$ & 2 & 2.08 & $+4 \%$ \\
$\mathrm{fr}(\mathrm{kHz})$ & 112.8 & 107.4 & $-4.8 \%$ \\
\hline
\end{tabular}

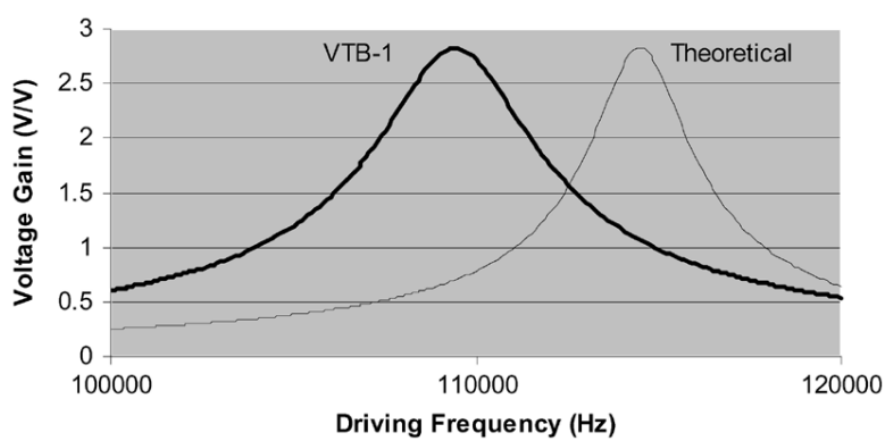

Fig. 14. Comparison of theoretical and measured steady-state voltage gains.

internal inductance and capacitance. However, the resonance frequency matches rather well. One possible reason for this difference is that the Transoner design equations assume perfect coupling between the primary and secondary layers. In addition, the manufacture of Transoner requires the addition of copper layers and adhesive, which may alter the performance of the complete piezoelectric transformer.

Further analysis reveals that the performance of the theoretical model and the measured model is very close. Figs. 14-16 show both the theoretical and actual performance, based on the equivalent circuit models, predicting voltage gain during steady state operation, efficiency, and inductor current, respectively, when a load of $500-\Omega$ is attached to the outputs. As can be seen from these plots, the actual performance agrees very well with the model prediction.

The custom-designed PT sample was used in the evaluation ballast circuit; Fig. 17 shows the prototype ballast circuit and the schematic diagram of the power circuit. The detailed description of the controller section can be found in [1]. Fig. 18 shows the waveform. By viewing the voltage that drives the piezoelectric transformer, one can determine whether or not the switches are operating in a zero voltage switching condition. The duty cycle for each switch is set to approximately $25 \%$. During the deadtime period, the current in the inductor charges/discharges the piezoelectric transformer input capacitor, $\mathrm{Cd} 1$ and the MOSFET drain-source capacitances. Here, one can see that the voltage transitions in a sinusoidal manner from the bus to ground during one portion of the dead-time period and from ground back to the bus during the other period. At the time when the transition tries to exceed the bus voltage or go below the ground reference, the body diode of the respective MOSFET conducts. During the

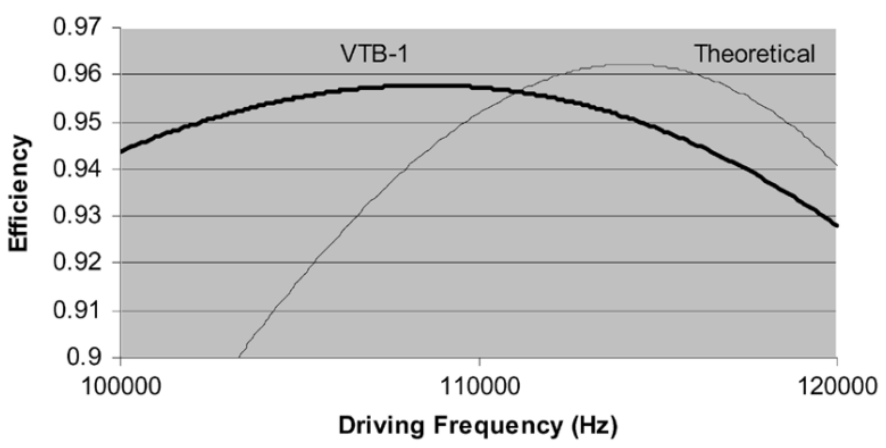

Fig. 15. Comparison of theoretical and measured efficiency.

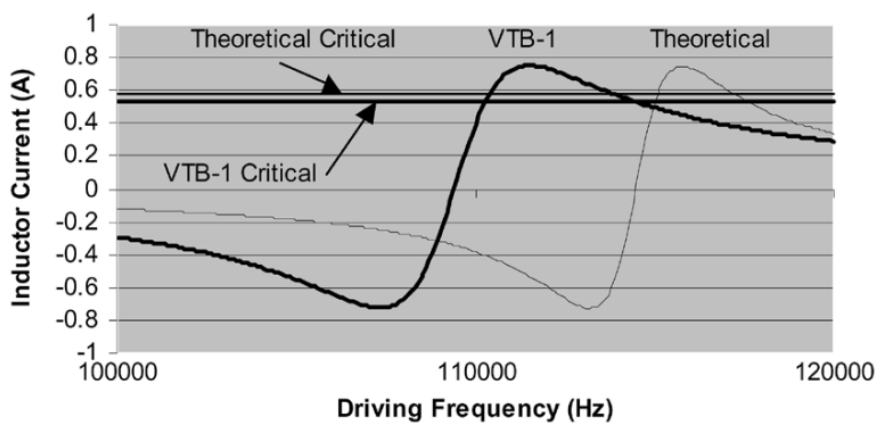

Fig. 16. Comparison of theoretical and measured inductor current. Where each inductor current exceeds its critical line, indicates a region of possible ZVS operation given the appropriate switch dead time.

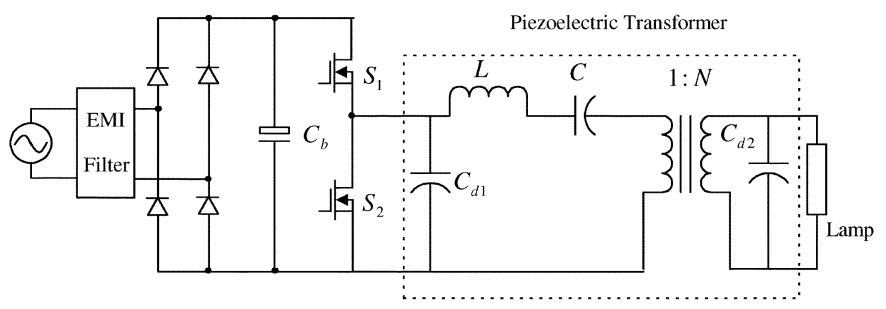

(a)

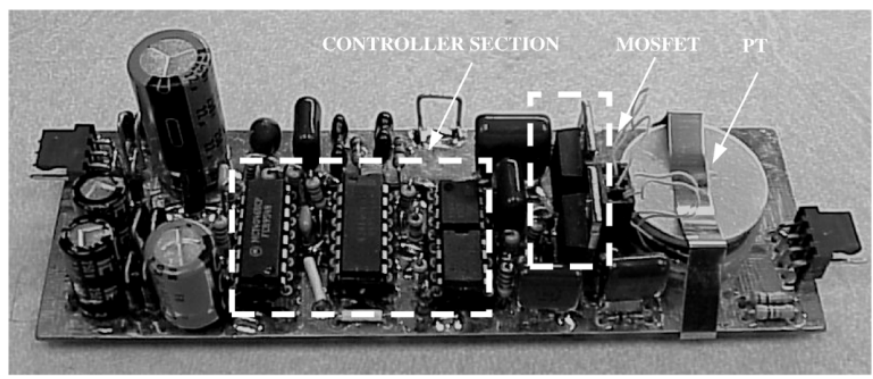

(b)

Fig. 17. (a) Simplified schematic of the prototype electronic ballast. (b) Prototype electronic ballast using piezoelectric transformer.

body diode conduction, the voltage across the switch is virtually zero. If the switch is turned on during this condition the turn-on switching losses are minimized. In the experiment that led to this waveform, the approximate efficiency of the inverter during the operation was $90 \%$. The efficiency of the PT was approximately $95 \%$. This leads to a combined efficiency of approximately $86 \%$ for the ballast at room temperature. The total losses were approximately $5 \mathrm{~W}$, with $1.7 \mathrm{~W}$ in the PT and $3.3 \mathrm{~W}$ 


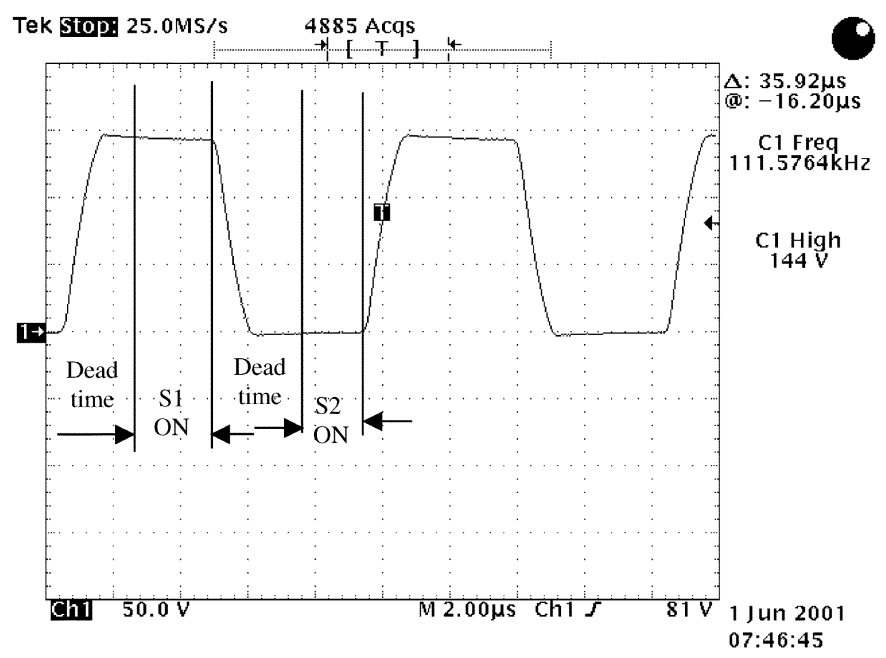

(a)

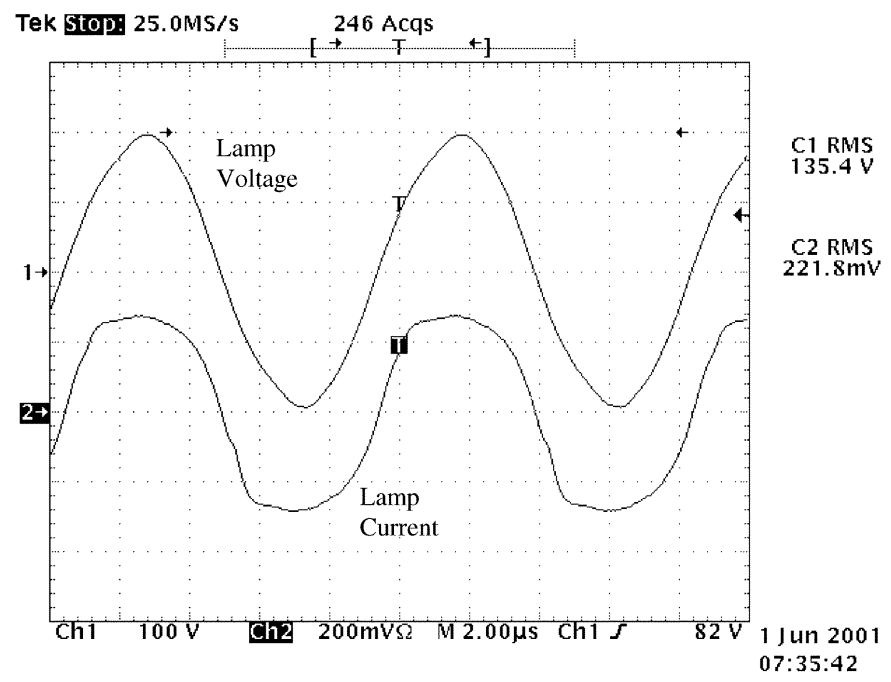

(b)

Fig. 18. (a) Bottom switch S2 drain-to-source voltage displaying ZVS operation. (b) Lamp voltage and current.

in the driving/control circuitry based on the efficiency calculations of the PT device.

\section{CONCLUSION}

The use of Transoner in fluorescent ballast applications has the potential to not only decrease size, weight, and cost, but also reduce electromagnetic emissions by eliminating the resonant inductor while simultaneously providing soft-switching. The Transoner design process described here can enable engineers to easily compare different geometries using a graphical method such that optimization and tuning of Transoner becomes a visual process. As can be seen from the results, the performance of the actual Transoner designed in this hypothetical application matches the performance of the theoretical model very well. The custom designed Transoner was also tested in the ballast circuit initially igniting then providing full power to an MEW FHF-32 fluorescent lamp, while concurrently enabling ZVS.

While the Transoner look promising for fluorescent lamp applications, it should be pointed out that there are disadvantages associated with this approach. These include relative low efficiency due to large internal resistance, inconvenience of adding filament preheating power in cases where this is necessary, and sensitivity to mechanical mounting methods. Further research is needed.

\section{ACKNOWLEDGMENT}

The authors would like to thank F. Tao, J. Zhou, and R.-L. Lin, for invaluable discussions and contributions leading to this paper, and all of the Staff Members of Face Electronics, for their efforts in providing the Transoner samples used in this research.

\section{REFERENCES}

[1] E. M. Baker, "Design of Radial Mode Piezoelectric Transformers for Lamp Ballast Applications," M.S. thesis, Virginia Tech, Blacksburg, May 2002.

[2] R. L. Lin, F. C. Lee, E. M. Baker, and D. Y. Chen, "Inductor-less piezoelectric transformer ballast for linear fluorescent lamps," in Proc. CPES Power Electronics Sem., Sep. 17-19, 2000, pp. 309-314.

[3] T. Zaitsu, "Power Conversion Using Piezoelectric Transformer," Ph.D. dissertation, Kyushu Univ., Fukuoka, Japan, Aug. 1997.

[4] E. M. Baker, J. Zhou, F. Tao, W. Huang, D. Y. Chen, and F. C. Lee, "Linear Ballast Development," Second Quarterly Rep. ELC-00-006, Dec. 30, 2000.

[5] C. Y. Lin, "Design and analysis of piezoelectric transformer converters," Ph.D. dissertation, Virginia Tech, Blacksburg, Jul. 1997.

[6] R. L. Lin, E. Baker, J. Wei, D. Y. Chen, and F. C. Lee, "Transoner Characterization,” Final Rep. ELC-99-007, Apr. 30, 2000.

[7] R. L. Lin, F. C. Lee, E. M. Baker, and F. C. Lee, "Characterization of piezoelectric transformers," in Proc. Power Electronics Sem., Blacksburg, VA, Sep. 19-21, 1999, pp. 219-225.

[8] R. P. Bishop, "Multilayer Piezoelectric Transformer," U.S. Patent 5834 882, Nov. 10, 1998.

[9] APC 841-Lead Zirconate Titanate, APC International Ltd. (2005). [Online]. Available: http://www.americanpiezo.com

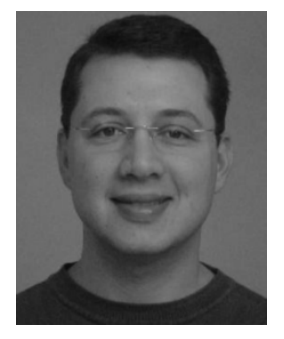

Eric M. Baker was born in Richmond, VA, in 1971. He received the B.S. degree in physics from Longwood College, Farmville, VA, in 1994 and the B.S. and M.S. degrees in electrical engineering from Virginia Polytechnic Institute and State University, Blacksburg, in 1999 and 2002, respectively.

Research topics have included the design and modeling of piezoelectric transformers as well as the associated control methodology when these devices are implemented in resonant power conversion. Since 2001, he has been an Electrical Design Engineer for Crown International, Elkhart, IN, where the major products are professional audio amplifiers. He works in the area of switched mode power conversion and his interests include power factor correction, resonant power conversion, and converter efficiency.

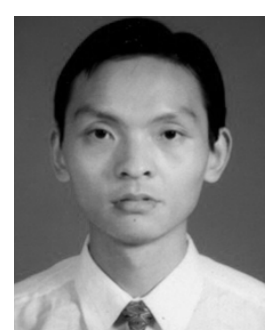

Weixing Huang was born in Wuhan, China, in 1976. He received the B.S.E.E. degree in electrical engineering from Huazhong University of Science and Technology, Huazhong, China, in 1997 and the M.S.E.E. degree in electrical engineering from Virginia Polytechnic Institute and State University (Virginia Tech), Blacksburg, in 2003.

He joined the Center for Power Electronics Systems (CPES), Virginia Tech, as a Research Assistant in 2000, Researching on piezoelectric transformer and associated power electronic circuits design. From 2002 to 2004, he worked at Sipex Corporation as an Application Engineer for their Power Management Product Line. Since 2004, he has been with Picor Corporation (a Subsidiary of Vicor Corporation), North Smithfield, RI, and is an Analog IC Design Engineer for Power ICs. 


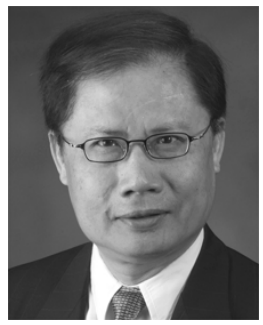

Dan Y. Chen (F'00) received the B.S.E.E. degree from National Chiao-Tung University, Hsinchu, Taiwan, R.O.C., in 1969 and the Ph.D. degree in electrical engineering from Duke University, Durham, NC, in 1975.

From 1975 to 1979 , he was with GE Corporate Research Center, Schenectady, NY, working on solid-state power applications including electronic ballasts for fluorescent lamps, electric cars, and switching power supply applications for computer and communication equipment. From 1979 to 2003, he was with the Electrical Engineering Department, Virginia Polytechnic Institute and State University (Virginia Tech), Blacksburg, and was a Core Professor at the National Science Foundation's Center for Power Electronic Systems. Since August 2003, he has been a Professor with the Electrical Engineering Department, National Taiwan University, Taipei. He has published one IEEE-press book, over 100 papers, one tutorial article in the IEEE Spectrum magazine, and holds seven U.S. patents all in the field of power electronics. His recent research interests include piezoelectric transformers, high power semiconductor device characterization, EMI in switching circuits, modern magnetic amplifier for switching power supplies, and power management IC architecture and design.

Dr. Chen received the IEEE Aerospace Society Barry Carlton Award in 1973 and the Best Paper Award of the 1998 IEEE Power Electronics Society.

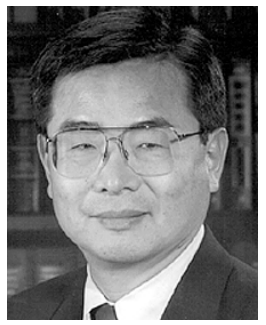

Fred C. Lee (S'72-M'74-SM'87-F'90) received the B.S. degree in electrical engineering from the National Cheng Kung University, Taiwan, R.O.C., in 1968 and the M.S. and Ph.D. degrees in electrical engineering from Duke University, Durham, NC, in 1971 and 1974, respectively.

He is a University Distinguished Professor with Virginia Polytechnic Institute and State University (Virginia Tech), Blacksburg, and prior to that he was the Lewis A. Hester Chair of Engineering at Virginia Tech. He directs the Center for Power Electronics Systems (CPES), a National Science Foundation engineering research center whose participants include five universities and over 100 corporations. In addition to Virginia Tech, participating CPES universities are the University of Wisconsin-Madison, Rensselaer Polytechnic Institute, North Carolina A\&T State University, and the University of Puerto Rico-Mayaguez. He is also the Founder and Director of the Virginia Power Electronics Center (VPEC), one of the largest university-based power electronics research centers in the country. VPEC's Industry-University Partnership Program provides an effective mechanism for technology transfer, and an opportunity for industries to profit from VPEC's research results. VPEC's programs have been able to attract world-renowned faculty and visiting professors to Virginia Tech who, in turn, attract an excellent cadre of undergraduate and graduate students. Total sponsored research funding secured by him over the last 20 years exceeds $\$ 35$ million. His research interests include high-frequency power conversion, distributed power systems, space power systems, power factor correction techniques, electronics packaging, high-frequency magnetics, device characterization, and modeling and control of converters. He holds 30 U.S. patents, and has published over 175 journal articles in refereed journals and more than 400 technical papers in conference proceedings.

Dr. Lee received the Society of Automotive Engineering's Ralph R. Teeter Education Award (1985), Virginia Tech's Alumni Award for Research Excellence (1990), and its College of Engineering Dean's Award for Excellence in Research (1997), in 1989, the William E. Newell Power Electronics Award, the highest award presented by the IEEE Power Electronics Society for outstanding achievement in the power electronics discipline, the Power Conversion and Intelligent Motion Award for Leadership in Power Electronics Education (1990), the Arthur E. Fury Award for Leadership and Innovation in Advancing Power Electronic Systems Technology (1998), the IEEE Millennium Medal, and honorary professorships from Shanghai University of Technology, Shanghai Railroad and Technology Institute, Nanjing Aeronautical Institute, Zhejiang University, and Tsinghua University. $\mathrm{He}$ is an active member in the professional community of power electronics engineers. He chaired the 1995 International Conference on Power Electronics and Drives Systems, which took place in Singapore, and co-chaired the 1994 International Power Electronics and Motion Control Conference, held in Beijing. During 1993-1994, he served as President of the IEEE Power Electronics Society and, before that, as Program Chair and then Conference Chair of IEEE-sponsored power electronics specialist conferences. 